This is an author produced version of a paper published in Acta Obstetrica et Gynecologica Scandinavia. This paper has been peer-reviewed but does not include the final publisher proof-corrections or journal pagination.

Citation for the published paper:

Liedman, Ragner and Skillern, Laurence and James, Ian and McLeod, Alison and Grant, Lee and Akerlund, Mats.

"Validation of a test model of induced dysmenorrhea" Acta Obstetrica et Gynecologica Scandinavia, 2006, Vol: 85, Issue: 4, pp. 451-57

http://dx.doi.org10.1080/00016340500432432

Access to the published version may require journal subscription.

Published with permission from: Blackwell Munksgaard 


\title{
Validation of a test model of induced
}

\section{dysmenorrhoea}

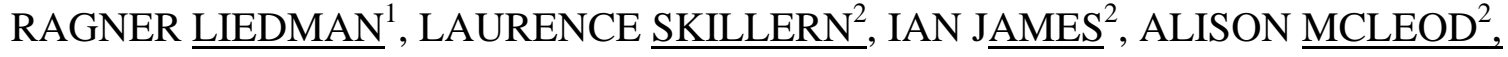

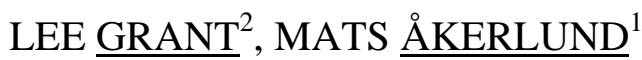

From the ${ }^{1}$ Department of Obstetrics and Gynecology, University Hospital of Lund, Sweden and ${ }^{2}$ Pfizer Global Research, Clinical Research and Development, Sandwich, UK

Address correspondence and reprint requests to: Professor Mats Akerlund, Department of Obstetrics and Gynaecology, University Hospital, S-221 85 Lund, Sweden. E-mail: mats.akerlund@gyn.lu.se

Short title: A test model of dysmenorrhoea. 


\section{ABSTRACT}

Background. The myometrial hyperactivity and reduced uterine blood flow of primary dysmenorrhoea is to a large extent caused by increased vasopressin secretion. A new therapeutic approach for this condition is to develop antagonists of uterine vasopressin $V_{1 a}$ receptors. We studied a test model of vasopressin-induced dysmenorrhoea in healthy, sterilised women and compared responses against those in dysmenorrheic subjects.

Methods. Eight women with primary dysmenorrhoea and eight sterilised, healthy women participated in recordings of intrauterine pressure and experienced pain on days 1-2 of two menstruations. We tried to identify biochemical markers in plasma of uterine ischemia. Furthermore, the effects of repeated bolus injections of $10 \mathrm{pmol} / \mathrm{kg} \mathrm{b} \mathrm{w}$ of vasopressin or placebo on these parameters were assessed.

Results. The vasopressin injections caused statistically significant increases in the area under the intrauterine pressure curve (AUC) in both healthy volunteers and patients with dysmenorrhoea, the overall responses being greater in healthy volunteers. The experienced pain measured by visual analogue scale (VAS) in individual dysmenorrhoeic subjects tended to show higher maximal post dose scores for the vasopressin injections than for placebo. Maximum VAS scores and maximum AUCs in individual subjects tended to be related. Mean CKMB levels were higher in women with dysmenorrhoea than in healthy subjects both before and after vasopressin administration, the converse being observed for CRP levels.

Conclusions. The present model appears to be useful for evaluating new drugs for the treatment of primary dysmenorrhoea.

Key words: primary dysmenorrhoea; vasopressin; intrauterine pressure; uterine ischemia markers 


\section{INTRODUCTION}

Primary dysmenorrhoea causes much discomfort, particularly in young, non-parous women of whom more than $50 \%$ suffer from the disease (1). The pain of this condition is associated with myometrial hyperactivity and reduced uterine blood flow (2), changes which apparently to a large extent are caused by increased secretion of arginine vasopressin (3-6). Stimulation of the release of endometrial prostaglandins may also be an effect and the importance of contractile prostaglandins in the condition is well-established $(7,8)$. Vasopressin exerts its uterine effects mainly via the vasopressin $\mathrm{V}_{1 \mathrm{a}}$ receptor (9-12). The aetiological importance of vasopressin in dysmenorrhoea was confirmed by the therapeutic effect of the peptide analogue 1-deamino-2-D-Tyr(Oet)-4-Thr-8-Orn-oxytocin, which competitively blocks the vasopressin $V_{1 a}$ and oxytocin receptors of the uterus (13) An orally active vasopressin $V_{1 a}$ and oxytocin receptor blocking agent, SR 49059, was also shown to inhibit vasopressin effects on uterine contractility and to be therapeutically active in dysmenorrhoea when given prophylactically before the onset of symptoms $(14,15)$.

There is a need for validated methodologies to facilitate the development of novel therapeutics, such as vasopressin $\mathrm{V}_{1 \mathrm{a}}$ receptor antagonists for the treatment of primary dysmenorrhoea. Methods for scoring uterine contractility and pain in dysmenorrhoeic women are already well tested and shown to be appropriate (2, 5, 6, 12, 14). However, biochemical markers of uterine ischemia may be a useful alternative which warrants further exploration. For testing new pharmacological agents for the treatment of dysmenorrhoea, healthy sterilised women could be preferable to patients with primary dysmenorrhoea $(11,12,14)$. There are several reasons for this: the uterine activity pattern in the former type of subjects is probably more consistent, they can not become pregnant during an experimental series, they are 
generally older and probably more capable of following a research program and their cervical canal is wider, allowing a more easy insertion of a recording catheter into the uterus.

In the present study we tested a model with sterilised women for evaluating vasopressin $\mathrm{V}_{1 \mathrm{a}}$ antagonists to be developed for the treatment of primary dysmenorrhoea. The aim was to determine the validity and reproducibility of measuring intrauterine pressure, pain and biochemical markers of uterine ischemia at early menstruation in women with dysmenorrhoea compared with healthy subjects. Furthermore, we studied the effect of repeated bolus injections of vasopressin and placebo on uterine activity, lower abdominal pain and ischemia markers at early menstruation in the same population.

\section{MATERIAL AND METHODS}

\section{Subjects}

A total of 16 women participated in the study. Eight of them suffered from moderate to severe dysmenorrhoea, defined as a history of at least 6 months of painful menstruations necessitating drug therapy. The age in this group ranged from $21-29$ years (mean 23.3 years), the women were all regularly menstruating and non-overweight (BMI < 27). All were nulliparous and used contraceptives, although not an intrauterine device or hormonal contraception within three calendar months before the start of the study. Another eight healthy, regularly menstruating, non-overweight, non-pregnant women aged 36 - 42 years (mean 39.6 years) participated in the "control” group. They were all parous and had undergone voluntary sterilisation by tubal division at laparoscopy; at this time they had been found to be gynaecologically normal. All women gave their written consent to participation. The study was conducted according to ICH guidelines and was approved by the local Ethics Committee. 


\section{Study design}

A prospective, double blind, two periods, crossover study was performed. The study included three phases, a screening phase, a study period phase (including two visits) and a follow-up phase. At each study period three intravenous bolus injections of vasopressin or placebo were given and the study was double-blinded regarding drug administration. The primary study endpoint was the effect on uterine activity and secondary endpoints were pain and plasma ischemia markers.

\section{Experimental procedure}

At a screening visit all participating women underwent a general physical and gynaecological examination, a pelvic ultrasound, routine blood and urine safety tests, HIV and hepatitis-A/B serology, chlamydia testing, and a 12 lead-electrocardiogram. Urine pregnancy tests were performed in the dysmenorrhoea group at screening and follow up as well as prior to all invasive procedures on study days.

After the screening visit participating subjects underwent a first recording of uterine contractility and experienced pain within the first 48 hours after the onset of menstruation. A second recording was performed at a usually consecutive menstruation. The recording sessions lasted for 220 minutes. The uterine contractility was measured as intrauterine pressure, which was recorded by a micro-transducer catheter (Millar Instruments Inc. Houston, Texas, USA) as previously described (16). The pressure signals were stored in a computer (Software from Synectics AB, Stockholm, Sweden) connected to an A/D signal converter (Polygraaf 12 Bit, Synectics AB, Stockholm, Sweden). A visual analogue scale 
(VAS, Innovaderm DVAS10) was used for measuring pain where the endpoints were scores that ranged between 00.0 (no pain) and 99.9 (worst menstrual pain which the patient had experienced). The women had an indwelling venous catheter placed in each arm. One of these catheters was used for administration of the study drugs and the other for blood sampling.

All subjects were given three intravenous bolus injections over 1 minute of either 10 $\mathrm{pmol} / \mathrm{kg} \mathrm{b} \mathrm{w}$ of vasopressin in $0.9 \mathrm{~mL}$ of $5 \%$ glucose or $0.9 \%$ saline (placebo) of the same volume. Infusions were prepared at the hospital pharmacy and administered double-blinded. During each study period, the subjects received, in a randomised manner, at least one injection of vasopressin (A) and one of placebo (B) according to the following sequences.

\section{$1^{\text {st }}$ study period $\quad 2^{\text {nd }}$ study period}

\begin{tabular}{lll}
\hline Sequence 1 & ABB & AAB \\
Sequence 2 & BAA & BBA \\
Sequence 3 & AAB & ABB \\
Sequence 4 & BBA & BAA
\end{tabular}

The first injection was given after 40 minutes, with further injections at 100 and 160 minutes after the start of recording.

The area under the curve (AUC) for uterine pressure was derived over 10-minute intervals throughout the study period. During the recording the participating women were also asked to record their pain experience in 2 min intervals for 10 min before and 10 min after each injection. Blood samples were taken for analyses of ischemic markers ( $\mathrm{C}$ reactive protein, CKMB isoenzyme and isoforms, CK, troponin-T and hypoxanthine) and vasopressin at 5 min before and 15 min after each injection, 60 min after the last injection and at follow up.

After the study period a follow-up visit was performed within 14 days. At this visit, physical and gynaecological examinations (including pelvic ultrasound and 
electrocardiogram) were performed and blood and urine samples taken for laboratory safety tests.

\section{Statistical methods}

The uterine pressure AUC post dose and the changes in uterine pressure AUC (post dose - pre dose) were analysed by a residual maximum likelihood (REML) analysis, with random effects: subject and study period within subject and fixed effects: study period, session, treatment, subject status (healthy or dysmenorrhoeic), treatment by subject status interaction and included pre dose AUC as a covariate. A logarithmic (log) transformation of AUC was used. The VAS score recorded for patients with dysmenorrhoea were visually assessed. As the healthy volunteers only experienced discomfort and not pain as the vasopressin was administered it was decided to disregard the healthy volunteer VAS data. The maximum post dose VAS was calculated. The uterine pressure AUC calculated for each two-minute interval during 10 minutes after each injection was plotted against the corresponding maximum VAS.

The sample size was determined based on our previous experience gained from exploratory studies with uterine measurements conducted previously by the centre, rather than formal power calculations.

\section{RESULTS}

All women who participated in the study had normal examinations both at screening and at the follow up visit. They completed the study successfully.

Representative recordings of intrauterine pressure and the effect of intravenous vasopressin and placebo injections in a patient with primary dysmenorrhoea and a healthy 
volunteer are shown in Fig. 1. The vasopressin injections generally caused an increase in uterine contractility with increased contraction frequency and basal tone for about 20 minutes, whereas no effect of placebo injections was observed. The average vasopressin - placebo baseline differences in log AUC of intrauterine pressure measurements in dysmenorrheic subjects (-0.24, SE: 0.09) and healthy volunteers (0.36, SE: 012) were found to be significantly different $(p=0.0013)$.

Log AUCs of intrauterine pressure recordings without and with pre dose AUC as covariate are shown in Table 1. The difference between vasopressin and placebo responses was statistically significant $(p<0.001)$ in all instances. Healthy volunteers responded to vasopressin with a larger increase in AUC than dysmenorrhoeic patients $(p<0.001)$. Analysis of AUC post dose also resulted in a highly significant treatment by status interaction $(p<0.001)$, implying that the treatment difference was larger for healthy volunteers than for patients. When AUC pre dose was taken into account and AUC (post dose - pre dose) was analysed, there was only a trend in the treatment by status interaction $(\mathrm{p}=0.104)$.

A plot of maximum VAS post-dose versus the corresponding log AUC for dysmenorrheic individual subjects is shown in Fig. 2. A trend towards a proportional relationship between these variables was observed, although the number of observations was too limited to allow formal statistical analyses. The change in maximum VAS score following vasopressin and placebo administrations is shown in Table 2. Following vasopressin the mean change was substantially greater than after placebo (statistical comparison not performed due to limited number of observations).

Ischemic markers were analysed in all eight subjects in the healthy volunteer group. In the dysmenorrhoea group samples from five subjects of the first study period were analysed and two from the second experimental series. The remaining samples were lost due to breakdown of a freezer. Results in CKMB are shown in Table 3 and CRP in Table 4. Regarding mean 
plasma CKMB concentrations, the values before and after vasopressin injections in dysmenorrheic women were numerically higher than the corresponding values in healthy volunteers. The opposite was found for mean plasma CRP concentrations. No statistically significant differences between pre- and post-dose levels were found for either CKMB or CRP in any group. No significant differences within or between groups were observed for the other ischemic markers.

\section{DISCUSSION}

There was a highly statistically significant treatment difference in intrauterine pressure between vasopressin and placebo injections in both patients and healthy volunteers. A comparison of the two subject groups showed a highly significant treatment by status interaction in AUC post-dose, which was larger for healthy volunteers than for patients. This difference between groups may reflect age related differences or, more probably, changes in uterine activity due to a thicker myometrium caused by previous pregnancy. However, when AUC pre-dose was taken into account, there was only a suggestion of a trend for a treatment by status interaction. Therefore, it would appear that although this model can detect a treatment difference between vasopressin and placebo in either patients or healthy volunteers, it seems to be less able to differentiate between the two subject groups.

The healthy volunteers only experienced discomfort and not pain with the increased AUC of intrauterine pressure, when vasopressin was administered. This was probably due to their parity, a well-known observation in gynaecologic practice. The effect mechanism is probably denervation of the uterus during pregnancy (17). It was therefore decided to disregard the healthy volunteer VAS data. Although there was no consistent relationship between maximum VAS pain score and maximum AUC, there was a trend towards a directly 
proportional relationship between these variables. However, the numbers analysed in this instance were too small to allow a formal statistical analysis. For the change in max VAS pain score following administration of vasopressin or placebo, the mean change in score following vasopressin administration was higher. This is in agreement with an aetiological importance of vasopressin-induced elevation of intrauterine pressure in primary dysmenorrhoea (3-6).

Uterine ischemia is most probably involved in the aetiology of pain in dysmenorrhoea, but the techniques previously used for measuring uterine blood flow based on thermodilution only give a semi-quantitative estimate of the flow (2). We therefore studied possible biochemical markers for uterine ischemia. In the absence of any known markers of uterine ischemia, we studied ischemic markers for heart and brain. There were no numerical differences between the groups except regarding $\mathrm{CKMB}$, which was higher in the group with primary dysmenorrhoea than the healthy subjects and CRP concentrations, which were lower in the former group. No significant difference was seen between levels before and after vasopressin injections in either group. These markers may represent potential disease / severity classification markers although their specificity remains to be elucidated. The different ages of the control and disease group as well as the small number of blood samples from women with dysmenorrhoea limit any reliable interpretation.

The treatment for dysmenorrhoea is presently analgesics and prostaglandin antagonists, but sufficient pain relief is only obtained in about $70 \%$ of subjects with this treatment (18). Drugs that specifically block the effects of vasopressin on the uterus could therefore be an alternative to available therapies. In the present validation study of a test model of induced dysmenorrhoea we found differences in uterine activity in both women with dysmenorrhoea and healthy subjects following administration of either vasopressin or placebo. However, this technique at present appears less able to differentiate between women with dysmenorrhoea and healthy subjects when given either vasopressin or placebo. In conclusion, the results of 
this pilot study appear to offer a methodology that can be considered for use in further studies for evaluating new drugs for the treatment of primary dysmenorrhoea. However, some further investigation and evaluation is needed applying drug candidates.

\section{ACKNOWLEDGEMENTS}

This study was sponsored by Pfizer Limited, Sandwich, United Kingdom. Mrs Alison Mcleod and Drs James, Skillern and Grant are employees of Pfizer Limited. The other authors are supported by grants from the company.

The authors acknowledge senior CRAs Richard Allen and Jeanette Fall for their skilful monitoring of the study and also biochemical analysts Louise Lindau and Bodil Nilsson for their excellent assistance during the study. 


\section{REFERENCES}

1. Widholm O, Kantero RL. Menstrual patterns of adolescent girls according to the chronological and gynaecological ages. Acta Obstet Gynecol Scand Suppl 14 1971; 50: 1929.

2. Åkerlund M, Andersson K-E, Ingemarsson I. Effects of terbutaline on myometrial activity, endometrial blood flow and lower abdominal pain in women with primary dysmenorrhoea. Br J Obstet Gynaecol 1976; 83: 673-8.

3. Åkerlund M, Strömberg P, Forsling ML. Primary dysmenorrhoea and vasopressin. Br J Obstet Gynaecol 1979; 86: 484-7.

4. Strömberg P, Åkerlund M, Forsling ML, Granström E, Kindahl H. Vasopressin and prostaglandin in premenstrual pain and primary dysmenorrhoea. Acta Obstet Gynecol Scand 1984; 63: 533-8.

5. Ekström P, Forsling ML, Kindahl H, Åkerlund M. Perception of pain of primary dysmenorrhoea in relation to uterine activity and plasma concentrations of vasopressin and a PG F2 a metabolite. J Neuroendocrinol, 4th International Conference on the Neurohypophysis, pp 168 - 171, 1990.

6. Ekström P, Laudanski T, Mrugacz G, Forsling M, Kindahl H, Åkerlund M. Stimulation of vasopressin release in women with primary dysmenorrheoa and after oral contraceptive treatment - effect on uterine contractility. Br J Obstet Gynaecol 1992; 99 :680-4.

7. Lumsden MA, Kelly RW, Baird DT. Primary dysmenorrhoea: the importance of both prostablandins $\mathrm{E}_{2}$ and $\mathrm{F}_{2 \alpha}$. Br J Obstet Gynaecol 1983; 90: 1135-40.

8. Lundström V, Gréen K. Endogenous levels of prostaglandin $F_{2 \alpha}$ and its main metabolites in plasma and the endometrium of normal and dysmenorreic women. Am J Obstet Gynecol 1978; 130: 640-6. 
9. Jard S, Elands J, Schmidt A, Barberis C. Vasopressin and oxytocin receptors: an overview. In: Imura $\mathrm{H}$ and Shirzune K, eds. Progress in Endocrinology. Amsterdam: Exerpta Medica, 1988: $1183-8$.

10. Thibonnier M, Auzan C, Madhun Z, Wilkins P, Berti-Matera L, Clauser E. Molecular cloning, sequencing, and functional expression of a cDNA encoding the human V1a vasopressin receptor. J Biol Chem 1994; 69: 3304-10.

11. Åkerlund M, Haukson A, Lundin S, Melin P, Trojnar J. Vasopressin analogues which competitively inhibit vasopressin stimulated uterine activity in healthy women. Br J Obstet Gynaecol Scand 1986; 93: 22-7.

12. Bossmar T, Åkerlund M, Fantoni G, Maggi M, Szamatowics J, Laudanski T. Receptormediated uterine effects of oxytocin and vasopressin in non-pregnant women. $\mathrm{Br} \mathrm{J}$ Obstet Gynaecol 1995; 102: 907-12.

13. Åkerlund M. Can primary dysmenorrhoea be alleviated by a vasopressin antagonist? Acta Obstet Gynecol Scand 1987; 66: 459- 61.

14. Bossmar T, Brouard R, Döberl A, Åkerlund M. Effects of SR 49059, an orally active vasopressin $\mathrm{V}_{1 \mathrm{a}}$ receptor antagonist on vasopressin-induced uterine contractions in women. Br J Obstet Gynaecol 1997; 104: 471-7.

15. Brouard R, Bossmar T, Fournié-Lloret D, Chassard D, Åkerlund M. Effect of SR 49059, an orally active vasopressin $\mathrm{V}_{1 \mathrm{a}}$ receptor antagonist, in the prevention of dysmenorrhoea. $\mathrm{Br} \mathrm{J}$ Obstet Gynaecol 2000; 107: 614-9.

16. Åkerlund M, Bengtsson LPh, Ulmsten U. Recording of myometrial activity in the nonpregnant uterus by a microtransducer catheter. Acta Obstet Gynecol Scand 1978; 57: 42933. 
17. Owman C, Alm P, Björklund A, Thorbert G. Extensive symphatetic denervation of the uterus during pregnancy as evidenced by tyrosine hyroxylase determination in the guinea pig. Adv Biochem Psychopharmacol 1980; 25: 313-20.

18. Dawood MY. Dysmenorrhoea. Clin Obstet Gynecol 1990; 33: 168-78. 


\section{LEGEND TO FIGURES}

Figure 1. Representative recordings of intrauterine pressure before and during intravenous injections of $10 \mathrm{pmol} / \mathrm{kg} \mathrm{b} \mathrm{w}$ of vasopressin (VP) and placebo (P) in a patient with primary dysmenorrhoea (upper panel) and in a healthy volunteer.

Figure 2. Maximum experienced pain (VAS recording) versus maximum Log AUC (over 2 minutes plotted for individual subjects). 


\section{TABLE 1.}

Mean log AUC (kPa x $10 \mathrm{~min}$ ) of intrauterine pressure recording curves over $10 \mathrm{~min}$ after vasopressin and placebo injections and log ratio with the pre-dose 10 min AUC as co-variate in women with primary dysmenorrhoea and in healthy volunteers. For vasopressin-placebo (VP-P) differences, $95 \%$ confidence intervals are given within brackets.

\section{Log AUC without pre dose AUC}

\begin{tabular}{|l|c|c|c|c|c|}
\hline & \multicolumn{2}{|c|}{ Means } & \multicolumn{3}{c|}{ Difference in Means } \\
\hline & Vasopressin & Placebo & Vaso-Pbo & $95 \%$ CI & P value \\
\hline Patients & 8.2 & 7.8 & 0.4 & $(0.19,0.51)$ & $<0.0001$ \\
\hline Healthy & 8.6 & 7.8 & 0.8 & $(0.61,1.03)$ & $<0.0001$ \\
\hline
\end{tabular}

\section{Log ratio with pre dose AUC as covariate}

\begin{tabular}{|l|c|c|c|c|c|}
\hline & \multicolumn{2}{|c|}{ Means } & \multicolumn{3}{c|}{ Difference in Means } \\
\hline & Vasopressin & Placebo & Vaso-Pbo & $95 \%$ CI & P value \\
\hline Patients & 0.37 & -0.03 & 0.39 & $(0.26,0.52)$ & $<0.0001$ \\
\hline Healthy & 0.55 & -0.002 & 0.55 & $(0.44,0.65)$ & $<0.0001$ \\
\hline
\end{tabular}




\section{TABLE 2.}

Maximum VAS score for the pre and post dose 10-minute intervals calculating the average max VAS for each individual and then calculating the overall mean for each treatment group.

\begin{tabular}{|l|r|r|r|r|r|r|}
\hline & \multicolumn{2}{|c|}{ Pre Dose } & \multicolumn{2}{c|}{ Post Dose } & \multicolumn{2}{c|}{ Post-Pre } \\
& Mean & SE & Mean & SE & Mean & SE \\
\hline Vasopressin & 40.63 & 2.96 & 48.63 & 4.56 & 8.00 & 4.51 \\
\hline Placebo & 38.20 & 5.04 & 37.28 & 6.26 & -0.93 & 1.85 \\
\hline
\end{tabular}




\section{TABLE 3}

CKMB levels pre dose (vasopressin or placebo), post dose, and the post - pre dose change in both patients and healthy volunteers.

\begin{tabular}{|l|l|r|r|r|r|r|r|r|r|r|}
\hline \multicolumn{2}{|c|}{} & \multicolumn{3}{c|}{ preckmb } & \multicolumn{3}{c|}{ ckmb } & \multicolumn{3}{c|}{ Post-Pre } \\
\cline { 3 - 11 } \multicolumn{2}{c|}{} & Mean & SE & N & Mean & SE & N & Mean & SE & N \\
\hline \multirow{2}{*}{ Patients } & Vasopressin & 0.99 & 0.25 & 4 & 1.13 & 0.24 & 5 & -0.02 & 0.03 & 4 \\
\cline { 2 - 11 } & Placebo & 1.05 & 0.20 & 5 & 1.07 & 0.18 & 5 & 0.02 & 0.03 & 5 \\
\hline \multirow{2}{*}{ Healthy Subjects } & Vasopressin & 0.66 & 0.05 & 8 & 0.65 & 0.04 & 8 & -0.02 & 0.02 & 8 \\
\cline { 2 - 11 } & Placebo & 0.66 & 0.05 & 8 & 0.65 & 0.05 & 8 & -0.01 & 0.01 & 8 \\
\hline
\end{tabular}




\section{TABLE 4}

CRP levels pre dose (vasopressin or placebo), post dose, and the post - pre dose change in both patients and healthy volunteers.

\begin{tabular}{|l|l|r|r|r|r|r|r|r|r|r|}
\hline \multicolumn{2}{c}{} & \multicolumn{3}{c|}{ precrp } & \multicolumn{3}{c|}{ crp } & \multicolumn{3}{c|}{ Post-Pre } \\
\cline { 3 - 13 } & Mean & SE & N & Mean & SE & N & Mean & SE & N \\
\hline \multirow{2}{*}{ Patients } & Vasopressin & 2.14 & 1.73 & 6 & 2.47 & 2.03 & 5 & -0.06 & 0.04 & 5 \\
\cline { 2 - 13 } & Placebo & 1.30 & 0.92 & 6 & 1.25 & 0.86 & 6 & -0.05 & 0.06 & 6 \\
\hline \multirow{2}{*}{ Healthy Subjects } & Vasopressin & 4.83 & 3.09 & 8 & 4.70 & 3.06 & 8 & -0.13 & 0.11 & 8 \\
\cline { 2 - 12 } & Placebo & 5.12 & 2.98 & 8 & 5.30 & 2.88 & 8 & 0.18 & 0.26 & 8 \\
\hline
\end{tabular}


FIGURE 1.
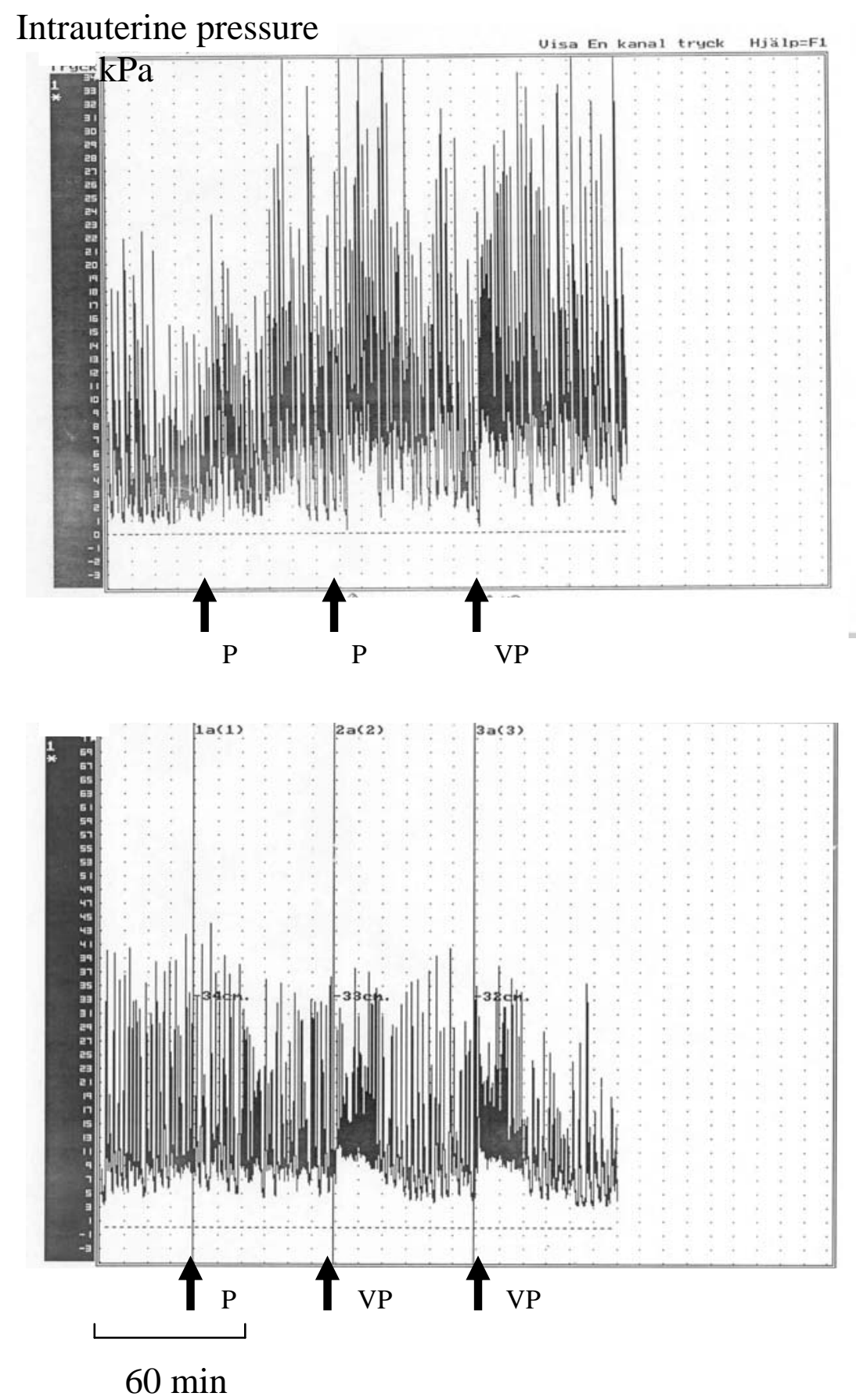
FIGURE 2.

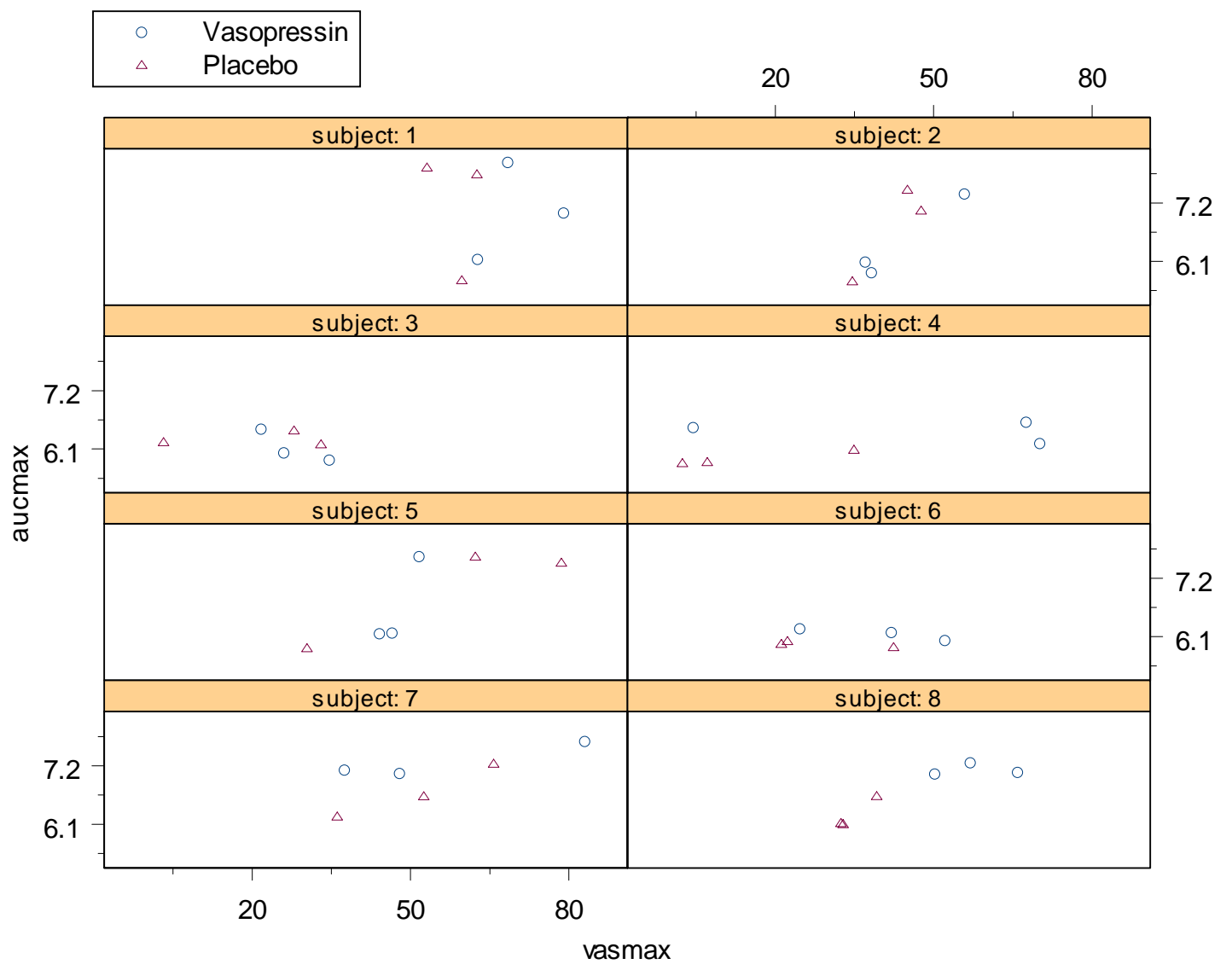

